\title{
Community-Based Questionnaires and Health Statistics as Tools for the Cost-Efficient Identification of Communities at Risk of Urinary Schistosomiasis
}

\author{
CHRISTIAN LENGELER, DONALd DE SAVIGNY," HASSAN MSHINDA," CHARLES MAYOMBANA, " \\ SEVERINO TAYARI," * CHRISTOPH HATZ,* ANTOINE DEGREMONT† AND MARCEL TANNERT
}

Lengeler C (Swiss Tropical Institute Field Laboratory, PO Box 53, Ifakara, Tanzania), de Savigny D, Mshinda H, Mayombana C, Tayari S. Hatz C. Degrémont A and Tanner M. Community-based questionnaires and health statistics as tools for the cost-efficient identification of communities at risk of urinary schistosomiasis. Internationa/ Jouma/ of Epidemiology 1991; 20: 796-807.

Self-administered questionnaires, distributed by existing administrative channels to villege party chairmen, headteachers and schoolchildren, showed good diagnostic performance for the qualitative assessment of urinary schistosomiasis endemicity.

At a cost 34 times below that of the WHO-recommended parasitological screening strategy, the schoolchildren's questionnaire allowed the screening of 75 out of 77 schools of a rural Tanzanian district in six weeks, and the exclusion of schools not at high risk for urinary schistosomiasis with over $90 \%$ confidence.

The headteacher and party questionnaires made it possible to assess the perceived importance of a spectrum of diseases and symptoms, among which was schistosomiasis. The priority rank of schistosomiasis control was strongly correlated with the prevalence rate of the disease in the community. The questionnaires also looked for the prioritization of health among other community issues and thus contributed important information for planning at district level.

Standardized monthly disease reports, sent by all primary health services, were also analysed. They allowed a zonal schistosomiasis endemicity classification.

Schistosomiasis is not associated with an acute illness, but with chronic, more or less painful debility. It therefore becomes a major public health problem only at a certain (community-specific) threshold. Schistosomiasis is transmitted focally and this results in variation in the level of infection between communities living in endemic areas. ${ }^{1}$ Comprehensive screening is therefore required before decisions regarding control can be made.

For the ranking of health priorities, quantitative data on the local spectrum of diseases is necessary. In

\footnotetext{
'Swiss Tropical Institute Field Laboratory, PO Box 53, Ifakara, Tanzania.

- District Health Office, PO Box 34, lfakara, Tanzania

tSwiss Tropical Institute, Department of Public Health and Epidemiology, Socinstrasse 57, CH-4051 Basle, Switzerland.

Reprint requests to: Dr M Tanner, Swiss Tropical Institute, PO Box 4002 , Basel, Switzerland.
}

this context the use of available health statistics and of simple community survey data for planning at district level has been advocated. ${ }^{2}$ But often available data are not properly standardized or complete, and even if they are, little use is made of them for planning at local level. ${ }^{3,4}$ Besides the decisions made by health professionals, based largely on health statistics and often reflecting national or international priorities, ${ }^{3}$ the perceptions and priorities of communities must also be considered. Experience with community diagnosis, 9,6 and with studies concerning malaria ${ }^{7.8}$ and schistosomiasis in Tanzania9,10 and elsewhere, ${ }^{11}$ shows that diseases and their main signs and symptoms are often well recognized and perceived by community members, and that this knowledge offers an important source of information for the setting of local priorities and for disease monitoring. ${ }^{12}$ In the Kilombero District, a comprehensive study of the occurrence and use of 
medicinal plants ${ }^{13}$ showed that a substantial traditional knowledge of disease and illness exists.

Matching control strategies with community disease perception will ensure the sustainability of control programmes within a primary health care framework. ${ }^{14}$ One approach in Tanzania investigated in detail the health status of a community and compared it to the priorities as perceived by the population. ${ }^{6}$ This information was then used for planning and executing an integrated schistosomiasis control programme. ${ }^{15}$ But such a comprehensive approach, as well as the parasitological screening approach recommended by WHO, would be too expensive and time-consuming for largescale screening in mainland Tanzania, where four million people in an area of over $500000 \mathrm{~km}^{2}$ are thought to be at risk. ${ }^{16}$ The present study was therefore carried out to investigate the value of the available health statistics and of simple community-based questionnaires for the rapid, indirect district-wide screening of health problems, with urinary schistosomiasis as the target disease.

\section{METHODS}

\section{Study Area}

The present research was undertaken in the Kilombero District of Morogoro Region, south-eastern Tanzania. The Kilombero District has been described in detail elsewhere. ${ }^{17,18}$ Most of its $15000 \mathrm{~km}^{2}$ lie in the Kilombero River plain, about $300 \mathrm{~km}$ inland from Dar-esSalaam. The 1988 national census gave a population figure of 187000 in 49 villages (including the suburbs of Ifakara, the main town), mainly engaged in subsistence farming. There were 77 primary schools, enrolling a total of 22108 students. Primary education is compulsory in Tanzania and the schooling rate was estimated at $90 \%$ at the time of the study. Malaria is holoendemic in the valley ${ }^{19}$ and many major tropical diseases occur. ${ }^{20}$ Schistosomiasis has been well investigated on the Kilombero sugar estates ${ }^{21}$ and around Ifakara. ${ }^{9,15.22}$ Most infections are due to Schistosoma haematobium, but two small foci of intestinal schistosomiasis exist in Namwawala ${ }^{23}$ and Kiberege (unpublished).

\section{District Health Statistics}

Routine statistics, returned monthly by all 18 dispensaries and the two health centres to the district health office in Ifakara, were analysed. The statistics, established by the Essential Drugs Programmes (EDP) in 1984, were compiled in each unit by the person in charge (a rural medical aid or a medical assistant) on standard forms used throughout Tanzania which include 23 clinical syndromes. One of them is 'schisto- somiasis', no difference being made between intestinal and urinary schistosomiasis. Data were also taken from the annual reports of the two hospitals (a parastatal hospital in Kidatu and the diocesan St Francis designated District Hospital in Ifakara). The number of 'schistosomiasis' cases for 1985, 1986 and 1987, the total number of cases and the incidence rates (cases per 1000 consultations) were calculated. When monthly results were missing for a unit an extrapolation to 12 months was done on the basis of a weighted average of the results that were available.

\section{School Questionnaires}

Two questionnaires investigating the disease perception of (i) primary school headteachers and (ii) schoolchildren were designed. Both questionnaires were pre-tested in two schools of Ifakara Town. Modifications concerning the presentation and wording were made after discussions with the teachers. Both questionnaires were written in Swahili and were very brief. They have been described in detail elsewhere. ${ }^{24}$ The one for the headteachers had six questions:

(1) the ranking of the diseases most prevalent among schoolchildren (chosen from: abdominal pain, diarrhoea, malaria, skin diseases, eye diseases, schistosomiasis, respiratory infections, measles, nutritional problems, worms, other)

(2) the ranking of the signs and symptoms most prevalent among schoolchildren (chosen from: coughing, itching, headache, fever, abdominal pain, wounds, blood in urine, blood in stool, convulsions, joint pains, diarrhoea, other)

(3) the ranking of priority diseases for control (no proposed list)

(4) the ranking of village problems (chosen from: water, agriculture, commodities, health, transport, sanitation, education, food, housing, milling machine)

(5)(6) questions on health facilities and water sources.

'Abdominal pain' and 'diarrhoea' were listed in both questions 1 and 2 , because the same word is used for describing both the disease and the symptom in Swahili. All necessary explanations were given in a short introduction at the beginning of the form.

The children's questionnaire was administered to all schoolchildren in classes one, three and five by a teacher. He asked the children individually and separately if they had experienced during the last month any of eight listed symptoms (coughing, itching, headache, fever, abdominal pain, blood in urine, blood in stool, diarrhoea) and eight diseases (malaria, diarrhoea, skin diseases, eye diseases, schistosomiasis, respiratory 
infections, worms, abdominal problems). The teachers recorded the children's answers as 'yes', 'no' or 'don't know' (counted as 'no' in the evaluation). The answers for each class (up to 35 children) were recorded. The rates of positive answers for 'blood in urine' and 'schistosomiasis' were later computed by our team, per class and per school.

\section{Distribution of the School Questionnaires}

The questionnaires were printed locally and distributed in August 1986 to all 77 primary schools by the District Education Office, together with its other administrative correspondence. Our team's input was limited to the design and production of the forms and to an extensive briefing of the District Education Officer. He was the only person who knew about the project's interest in schistosomiasis, since the exercise was presented to the teachers as community-problemoriented, and to the children as overall health-oriented.

\section{Local Government Questionnaire}

A questionnaire similar to the one for the headteachers was sent through the existing political party channels to all branch chairmen $(n=51)$ of the Chama Cha Mapinduzi Party (Party of the Revolution). The only modification was that they were asked to rank diseases and symptoms most prevalent in the village and not among schoolchildren.

\section{Parasitological Validation (Mobile Laboratory)}

An extensive parasitological screening survey was conducted by a mobile field laboratory team, after reception of all questionnaires. Urine filtration according to a standard procedure $e^{24}$ was performed, with $25 \mathrm{~mm}$ Nucleopore filters; gross haematuria was also recorded. A sample of 56 out of 77 primary schools were visited (Figure 1). All schools in suspected high and medium prevalence areas were screened as well as every second school in suspected low prevalence areas. For the latter, prevalence rates in the schools examined were consistently below $15 \%$, the geographical environment was not favourable for transmission, and teachers and village leaders had not mentioned schistosomiasis as a problem.

Testing in each school was restricted to children of classes two, three and four, in order to ensure agehomogeneity of the samples. In total, 4469 children were examined (mean $=85 \pm 15$ per school, range $=53-127)$. The male/female sex ratio was 0.96 and the mean age $12 \pm 2$ years (range 7-18), a population similar to the one investigated by the questionnaires (see below). Health education for children and extensive discussions with teachers were part of the survey routine. The team consisted usually of four people: one driver/clerk, two laboratory assistants and one senior staff member (experienced laboratory technician or parasitologist). Work was done on five days per week, one school being examined per day. All eggpositive children were treated with a single dose of Praziquantel $(40 \mathrm{mg} / \mathrm{Kg}$ ), either on-the-spot in the remote schools, or in a health unit (dispensary, health centre) when there was one in the village.

\section{Costing and Data Analysis}

The financial costs for the four screening procedures were recorded systematically: transport, recurrent supplies, allowances, salaries, travel and other costs; initial investments for equipment and treatment costs were not included. Neither did we include the teachers' and party chairmen's working time, as this was considered by the authorities to be part of their duties.

All survey data were analysed with the SPSS/PC+ statistical package (SPSS Inc., Chicago, USA), on an IBM-AT compatible personal computer, after extensive data entry checks (comparison with original documents, range and consistency checks).

\section{RESULTS}

\section{Urine Filtration Screening (Reference Approach)}

The systematic district-wide school screening with urine filtration in 56 primary schools provided the reference data for the evaluation of the three indirect approaches. Figure 1 shows all schools and indicates, for those which were screened parasitologically, whether the egg prevalence rate was above or below $25 \%$. Of the 4469 children tested, 957 were found to be egg-positive $(21.4 \%)$; 20 schools had a prevalence rate $\geqslant 25.0 \%$ (WHO-recommended threshold for moderate infection rates ${ }^{25}$ ) and four schools had a prevalence rate $\geqslant 50.0 \%$ (WHO-recommended threshold for high infection rates ${ }^{25}$ ). The median school prevalence rate was $13.1 \%$. Gross haematuria was seen in only $1.1 \%$ of the children and only three schools had a prevalence rate of visible haematuria $\geqslant 10.0 \%$. The parasitological data are detailed elsewhere. ${ }^{24}$

\section{District Health Statistics}

Standardized health statistics concerning schistosomiasis, collected in the 22 health service units of the district, are presented in Table 1. The two hospitals were excluded from the ranking according to cases 1000 consultations, because they offered very different medical services. Over the three years, an average of 2392 schistosomiasis cases were reported per year. The total number of cases was similar in 1985 


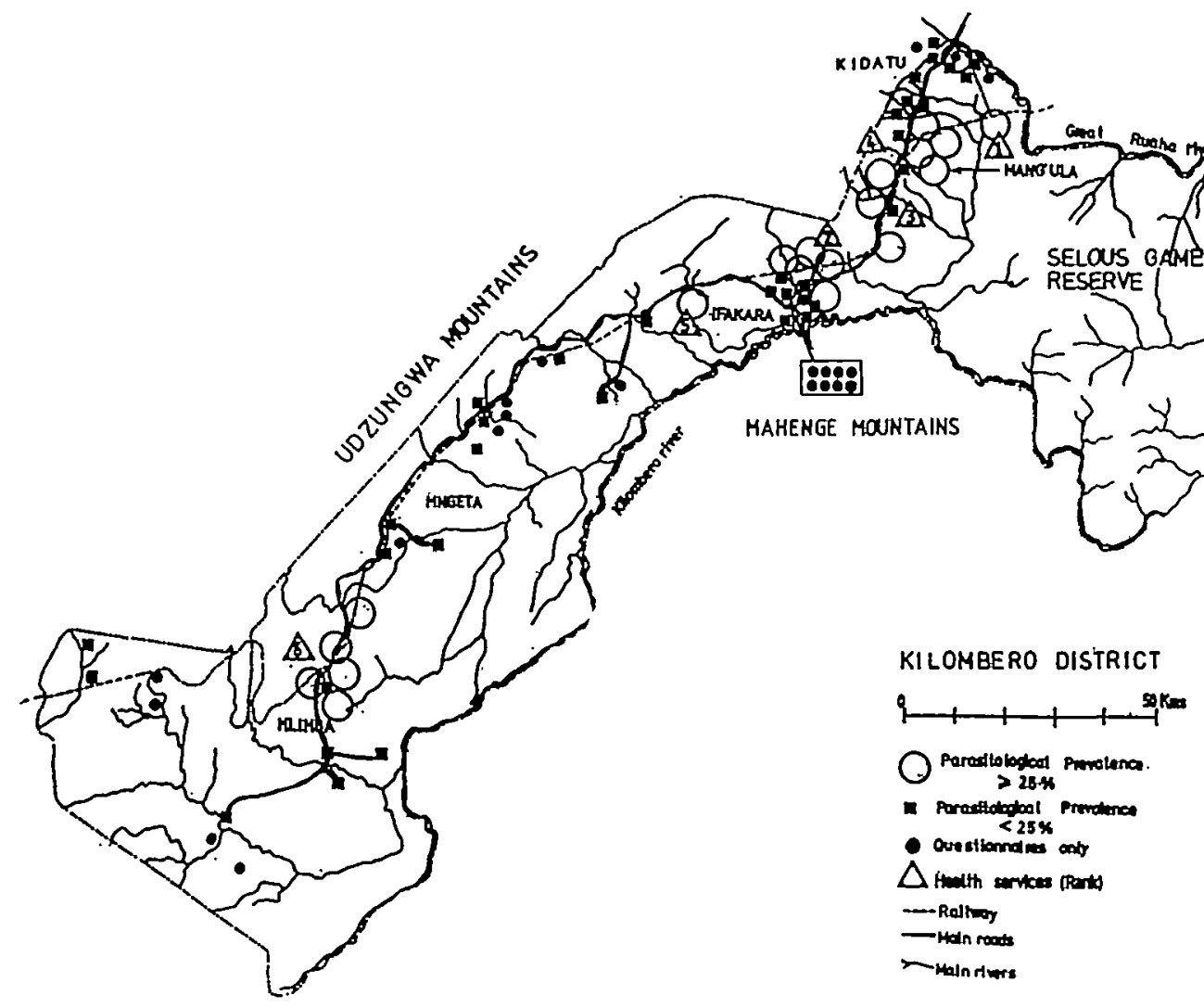

Figure 1 The Kilombero Distnct (south-eastern Tanzania), with all 77 primary schools and the six health services with the highest number of schistosomiasis cases/l000 consultasions (with their rank according to Table 1).

and 1986 (2057 versus 2135), with an increase of 343 cases for the dispensaries and health centres and a decrease of 265 cases and in the two hospitals. The increase in reported cases in 1987 was mainly due to the opening of the new Msolwa Stesheni dispensary, situated in a moderate risk area for schistosomiasis (school prevalence rate $42.6 \%$ ), and to Kibaoni and Idete dispensaries. No systematic investigation on the availability of diagnosis (microscopes) and drugs for treating schistosomiasis was made; however, they are normally available in the two hospitals, the two health care centres and the mission dispensaries.

The rate of diagnosed schistosomiasis cases per 1000 consultations was compared to the weighted mean school prevalence rate in the catchment areas of the health units (Figure 2). With the exception of the health unit of Kisawasawa, health service units situated in areas with a mean parasitological prevalence rate below $20 \%$ had a diagnosed case-rate below five cases 1000 . All six units (excluding Kisawasawa) situated in areas with a mean parasitological prevalence rate above $30 \%$ had a rate of diagnosed cases above eight cases $/ 1000$. The Spearman rank correlation coefficient for this association was significant $(r=0.79, p<0.001)$. The 'top six' health units were situated in the Kidatu, Mang'ula and Ifakara divisions, and in Mlimba town (Figure 1). No health service facilities in Mngeta and Mlimba rural divisions showed high reported case rates.

Headteachers' and Schoolchildren's Questionnaires Acceptance and return rates of both school questionnaires were remarkably high: $77777(100 \%)$ headteacher and $75 / 77(97.4 \%)$ student questionnaires were returned to the district education office within six weeks. This approach had the best district-wide coverage for the number of screened community units and individuals. Some 6772 children were interviewed by their teachers: 2481 in class one, 2181 in class three and 2110 in class five. The mean age was $12 \pm 2$ years and the sex-ratio 0.98 . An average of $90 \pm 20$ children were interviewed per school (range 36-137). A total of 1278 children declared that they had blood in their urine during the last month $(18.7 \%, 95 \%$ confidence 
TABLE 1 Diagnosed cases of schistosomiasis in all 22 health facilities of the Kilombero District, 1985-1987. No difference made between urinary and intestinal schistosomiasis. Services ranked according to cases of schistosomiass/1000 consultations

\begin{tabular}{|c|c|c|c|c|c|c|c|}
\hline Rank & $\begin{array}{l}\text { Health } \\
\text { services }\end{array}$ & & 1985 & 1986 & 1987 & $\begin{array}{l}\text { Total } \\
\text { cases }\end{array}$ & $\begin{array}{l}\text { Schistosomiasis } \\
\text { cases per } / 1000 \\
\text { consultations }\end{array}$ \\
\hline \multirow[t]{2}{*}{1} & Msolwa & & & & & & \\
\hline & Stesheni & GD & $n / a^{*}$ & $n / a^{*}$ & 600 & 600 & 19.5 \\
\hline 2 & Kibaoni & GD & 140 & 275 & 544 & 959 & 17.6 \\
\hline 3 & Kiberege & GD & 238 & 175 & 173 & 586 & 14.6 \\
\hline 4 & Mang'ula & GHC & 197 & 267 & 193 & 657 & 12.4 \\
\hline 5 & Idete & GD & 36 & 96 & 279 & 411 & 12.4 \\
\hline 6 & Mlimba & GHC & 120 & 132 & 94 & 346 & 8.8 \\
\hline 7 & Mofu & MD & 8 & 8 & 11 & 27 & 4.7 \\
\hline 8 & Msolwa & GD & 32 & 44 & 20 & 96 & 3.1 \\
\hline 9 & Kisawasawa & MD & 19 & 5 & 31 & 55 & 2.3 \\
\hline 10 & Mpanga & MD & 7 & 15 & 0 & 22 & 2.0 \\
\hline 11 & Utengule & GD & 0 & 119 & 18 & 137 & 1.6 \\
\hline 12 & Chita & GD & 24 & 24 & 15 & 63 & 13 \\
\hline 13 & Sonjo & GD & 19 & 13 & 11 & 43 & 1.3 \\
\hline 14 & Mchombe & MD & 2 & 10 & 24 & 36 & 1.1 \\
\hline 15 & Mbingu & GD & 3 & 9 & 11 & 23 & 1.1 \\
\hline 16 & Mkamba & GD & 4 & 1 & 35 & 40 & 1.0 \\
\hline 17 & Mngeta & GD & 3 & 2 & 23 & 28 & 0.9 \\
\hline 18 & Merera & MD & 4 & 2 & 4 & 10 & 0.7 \\
\hline 19 & Taweta & MD & 0 & 3 & 0 & 3 & 0.4 \\
\hline \multirow[t]{5}{*}{20} & Uchindile & GD & 0 & 0 & 0 & 0 & 0.0 \\
\hline & Total & & 855 & 1198 & 1708 & 4139 & 6.4 \\
\hline & \multirow{3}{*}{\multicolumn{2}{|c|}{$\begin{array}{l}\text { Hospital Ifakara } \\
\text { Hospital Kidatu } \\
\text { Total hospitals }\end{array}$}} & 378 & 364 & 341 & 1083 & 0.2 \\
\hline & & & 824 & 573 & 558 & 1953 & 0.2 \\
\hline & & & 1202 & 937 & 899 & 3038 & 0.2 \\
\hline
\end{tabular}

All health services 2057213526077177 (2392/year)

*not available

Note: GD-Government dispensary

MD-Mission dispensary

GHC-Government health centre

interval (CI): 17.1-19.6), and 1548 said that they had had schistosomiasis $(22.9 \%, 95 \%$ CI: $21.9-23.9)$.

In Table 2, Spearman rank correlation analysis of the questionnaire results with three parasitological parameters (egg prevalence rate, visible haematuria rate and mean geometric intensity of the positives) in 55 schools showed that question two of the children's questionnaire (frequency of answer 'yes, I had schistosomiasis') gave the highest correlations. All associations were statistically significant, except the teachers' questions one and two with the mean intensity of the positives. Figures $3 \mathrm{a}$ and $3 \mathrm{~b}$ show the correlations between the frequency of children stating that they had had 'blood in urine' or 'schistosomiasis' during the last month and the school prevalence rates.

The correlation between the two questions of the children's questionnaire was very significant when they were compared at the school level (Pearson linear cor- relation: $r=0.90, p<0.0001)$. But at the individual level, there was no concordance between the answers 'I had blood in my urine' and 'I had schistosomiasis' (McNemar test for paired values, $\mathrm{p}<0.00001$ ). This discordance was mainly due to the children stating that they had schistosomiasis, but not reporting blood in urine $(n=558)$, rather than the reverse $(n=268)$.

The diagnostic performance (sensitivity, specificity, predictive values according to Baye's theorem ${ }^{26}$ and diagnostic efficiency) of all questions for identifying schools with more than $25 \%$ and more than $50 \%$ prevalence rates, was assessed. Table 3 shows that for the identification of schools with more than a $25 \%$ prevalence rate, question three of the headteachers' questionnaire and question one of the children's questionnaire gave the best compromise between high sensitivity, specificity and predictive values. The results for the identification of high-risk schools ( $\geqslant 50 \% \mathrm{egg}$ prevalence rate) must be taken with caution, as only four schools were still positive at this threshold, and the sensitivity calculations therefore lack precision. All questions showed high negative predictive values at both prevalence thresholds $(82.8-100.0 \%)$. Test efficiencies were higher for the identification of high risk schools.

A remarkable picture is shown in Figure 4: Below an egg prevalence rate of $30 \%$, the majority of the headteachers, when asked about the priority diseases for control (question three), ranked schistosomiasis fourth or lower, and many did not even mention it (rank $=$ ninth). However, at an egg prevalence rate above $30 \%$, 15 out of 16 headteachers ranked schistosomiasis fourth or above. The one exception (Kikwawila: high prevalence rate, low rank) is the only village in the district where schistosomiasis control activities have been carried out already (in 1982$1984^{15}$ ) but where the egg prevalence rate in the schoolchildren was still high.

\section{Local Government Questionnaire}

Of the questionnaires distributed through the political party system, $44 / 51(86.3 \%)$ were returned within three months: 38 from villages and six from parastatal companies (who also have party branches). The results were analysed in a similar manner to the headteacher questionnaire, and question three (priority diseases for control) was also found to correlate best with the village prevalence rates (Spearman's $r=-0.64$, $p<0.001$ ). Sensitivity, specificity and predictive values were also similar for the detection of moderate and high endemicity villages, but they are not shown because the coverage was much lower (only 34 villages with both the questionnaire and the parasitological 


\section{AREA PREVALENCE RATE (\%)}

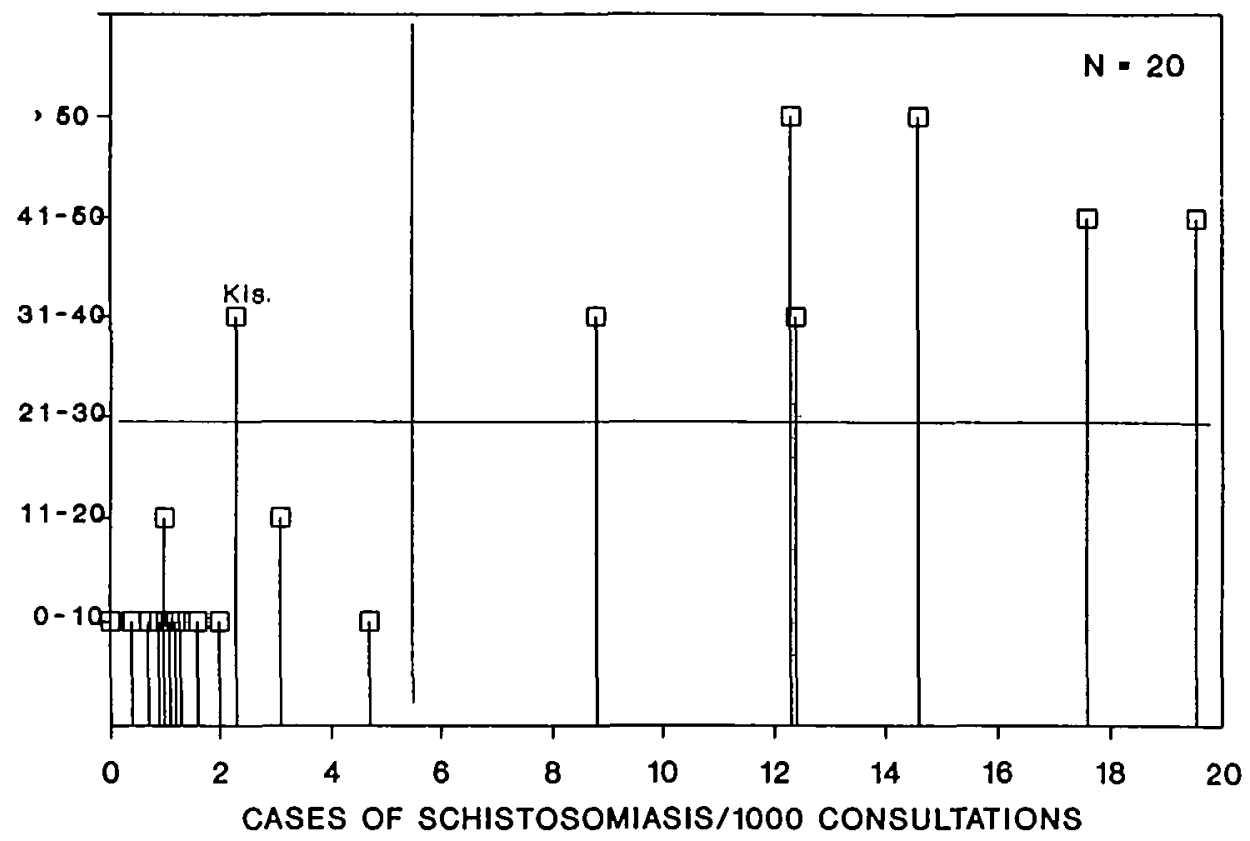

FIOURE 2 Diagnosed cases of schistosomiasis/1000 consultations in 20 pnmary health services of the Kilombero District, in relation to the mean urinary schistosomiasis prevalence rate in their catchment area. Kis. = Kisawasawa.

results); the precision of the measures was therefore lower.

Figure 5 shows that question three (priority diseases for control) of the party questionnaire also displayed a 'high priority' threshold at about a $43 \%$ prevalence rate; above this limit, schistosomiasis became a 'top five' priority disease in all seven villages concerned. The village of Namwawala (Nam.) has a low $S$. haematobium endemicity $(10.8 \%)$, but $56.2 \% S$. mansoni infections in schoolchildren.

A comparison between the answers given by the headteachers and the party chairmen for the same

TABiB 2 Spearman rank correlation coefficienis (and associased p values) for the relation between the school questionnaire answers and the school parasitological results

\begin{tabular}{|c|c|c|c|}
\hline & Egg prevalence & $\begin{array}{l}\text { ol parasitological re } \\
\text { Gross haematuria }\end{array}$ & Intensity* \\
\hline \multicolumn{4}{|c|}{ Headteachers' questionnaire $(n=56)$} \\
\hline Question 1 & 0.55 & 0.54 & 0.12 \\
\hline Rank 'schistosomiasis' & $(p<0.0001)$ & $(p<0.0001)$ & NS** \\
\hline Question 2 & 0.51 & 0.53 & 0.08 \\
\hline Rank 'blood in urine' & $(p<0.0001)$ & $(p<0.0001)$ & NS** \\
\hline Question 3 & 0.62 & 0.64 & 0.28 \\
\hline Rank 'control' & $(p<0.0001)$ & $(p<0.0001)$ & $(p<0.04)$ \\
\hline \multicolumn{4}{|l|}{ Children's questionnaire $(n=55)$} \\
\hline Question 1 & 0.67 & 0.39 & 0.36 \\
\hline Frequency 'blood in urine' & $(p<0.0001)$ & $(p<0.003)$ & $(p<0.007$ \\
\hline Question 2 & 0.75 & 0.51 & 0.37 \\
\hline Frequency 'schistosomiasis' & $(p<0.0001)$ & $(p<0.0001)$ & $(p<0,006)$ \\
\hline
\end{tabular}

"Geometric mean of positives

- NS = Not significant at $5 \%$ level 


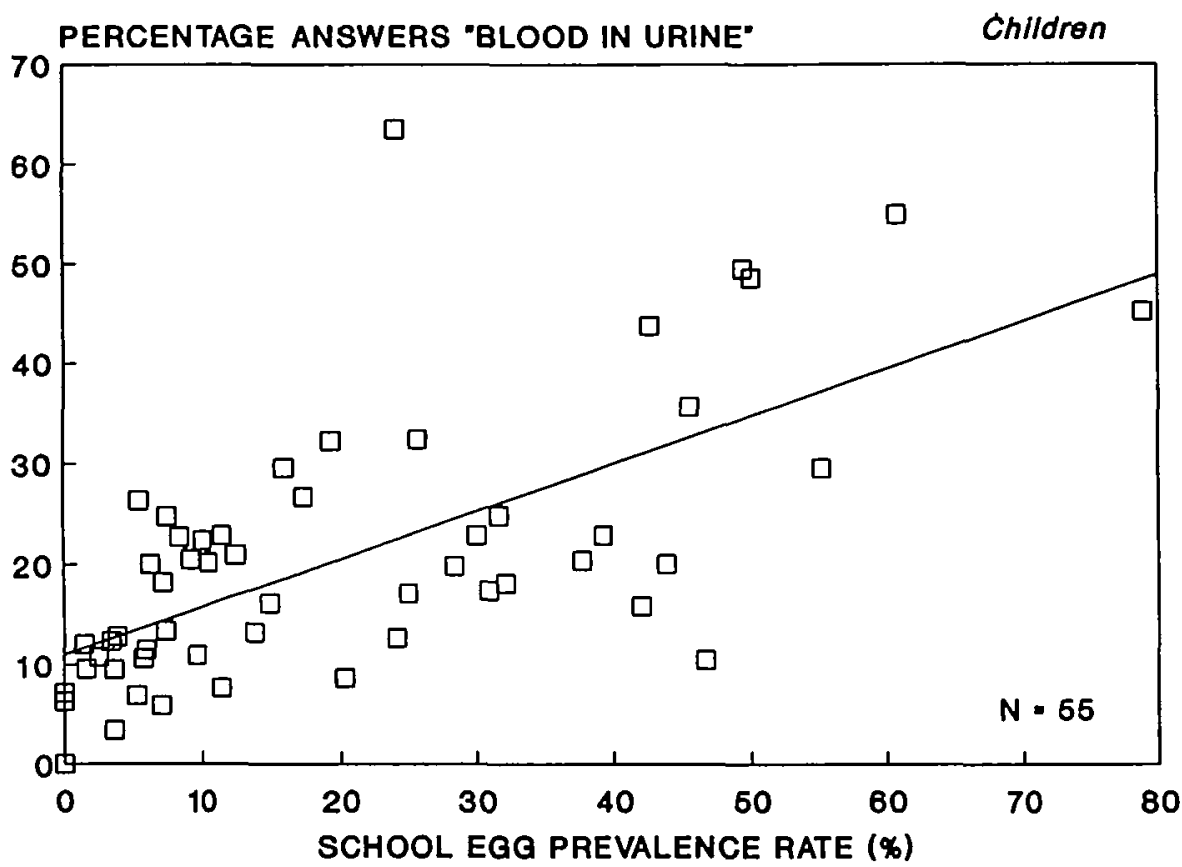

(a)

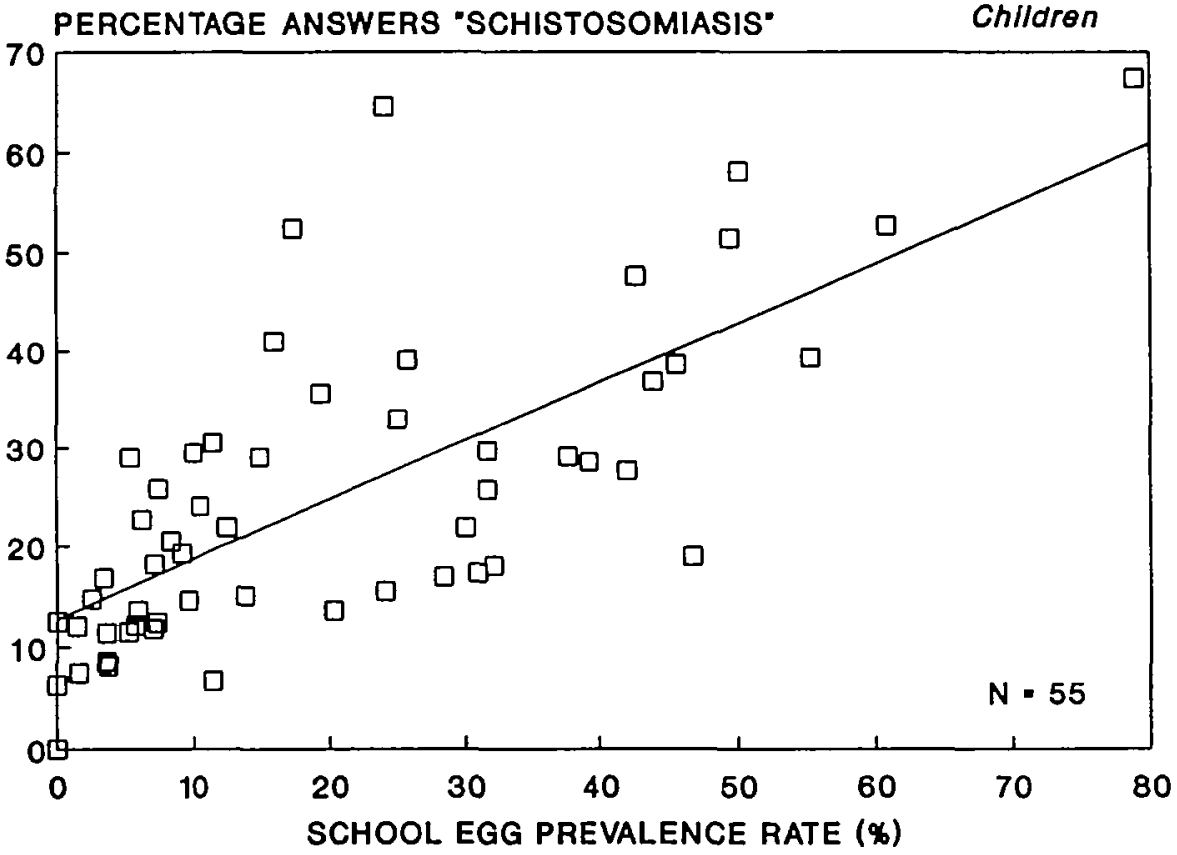

(b)

FigURE 3 Correlation (with regression line) between the school parasitological prevalence rate and the frequency of children answering 'I had blood in urine' (question one-Figure 3a) and 'I had schistosomiasis' (question two-Figure 3b), in 55 schools of the Kilombero District. 
TABLE 3 Diognostic performance of the headteachers' and the children's questionnaires for the identification of schools at moderate and high risk for urinary schistosomiasis. All values in per cent

\begin{tabular}{|c|c|c|c|c|}
\hline \multirow[b]{2}{*}{$\begin{array}{l}\text { Questionnaire } \\
\text { Number of schools } \\
\text { above threshold }\end{array}$} & \multicolumn{2}{|c|}{ Moderate risk (25\%) } & \multicolumn{2}{|c|}{ High risk (50\%) } \\
\hline & Headteacher & Children & Headteacher & Children \\
\hline \multicolumn{5}{|c|}{$\begin{array}{l}\text { Question } 1 \text { Teacher: rank of 'schistosomiasis' among } 11 \text { diseases } \\
\text { Children: trequency of reported 'blood in urine' }\end{array}$} \\
\hline Question threshold & Rank 5 & $15 \%$ & Rank 3 & $25 \%$ \\
\hline Sensitivity & 80.0 & 95.0 & 75.0 & 100.0 \\
\hline Specificity & 66.7 & 57.1 & 76.9 & 82.4 \\
\hline $\mathbf{P V}+$ & 57.2 & 55.9 & 19.9 & 30.9 \\
\hline PV- & 85.7 & 95.2 & 97.6 & 100.0 \\
\hline Efficiency & 59.9 & 56.5 & 72.5 & 78.7 \\
\hline \multicolumn{5}{|c|}{$\begin{array}{c}\text { Question } 2 \text { Teacher: rank of 'blood in urine' among } 12 \text { symptoms } \\
\text { Children: frequency of reported 'schistosomiasis' }\end{array}$} \\
\hline Question threshold & Rank 7 & $20 \%$ & Rank 3 & $35 \%$ \\
\hline Sensitivity & 75.0 & 80.0 & 750 & 100.0 \\
\hline Specificity & 66.7 & 62.9 & 80.8 & 82.4 \\
\hline PV+ & 55.6 & 55.2 & 23.0 & 30.9 \\
\hline PV - & 82.8 & 84.6 & 97.7 & 100.0 \\
\hline Efficiency & 58.4 & 56.8 & 76.3 & 78.7 \\
\hline \multicolumn{5}{|c|}{$\begin{array}{l}\text { Question } 3 \text { Teacher: priority rank of 'schistosomiasis' for control } \\
\text { Children: no question } 3\end{array}$} \\
\hline Question threshold & Rank 5 & - & Rank 4 & - \\
\hline Sensitivity & 90.0 & - & 75.0 & - \\
\hline Specificity & 66.7 & - & 53.8 & - \\
\hline PV+ & 60.0 & - & 11.0 & - \\
\hline PV- & 92.3 & - & 96.6 & - \\
\hline Efficiency & 62.9 & - & 50.6 & - \\
\hline
\end{tabular}

Note: $\mathrm{PV}+\rightarrow$ Positive predictive value

$P V-=$ Negative predictive value

Question threshold $=$ questionnaire positivity threshold (headteacher: last positive rank, children: minimum number of positive answers)

question three pointed out that headteachers gave a higher priority to schistosomiasis for control than the politicians; there were only two exceptions: Kisawasawa and Namwawala villages. Although there was a significant linear correlation between the two groups of respondents (Spearman rank correlation: $r=0.44$, $p<0.01$ ), the median rank given by the headteachers (4, 95\% CI: $2-6)$ was significantly higher than the median rank given by the politicians (8, 95\% CI: 7-9).

\section{Comparison of All Approaches}

Table 4 summarizes the main operational features of the four approaches. The school questionnaires gave the best district-wide coverage and the fastest screening time: 6772 children in 77 units were screened in six weeks at a cost of 270 USS, a sum 26.5 times lower per screened unit than the mobile laboratory approach.

\section{DISCUSSION}

Health statistics, collected routinely on a standardized form, showed an interesting potential for the detection of zones at risk for schistosomiasis. The available semiquantitative information is suitable for a first endemicity evaluation and for planning anti-schistosome drug supply at district level. The yearly fluctuation in the number of cases in the units suggests that more than one year should be used in an evaluation procedure. An evaluation at regional and national level will be necessary to determine what use can be made of the available routine data for national policy formulation. This approach could become the first step of a nationwide screening programme, making it possible to exclude areas where the disease has not been diagnosed and reported.

Our approach to using community disease perception as a diagnostic tool for urinary schistosomiasis differed from that of previous studies, ${ }^{28,29}$ in which people were interveiwed within the framework of schistosomiasis-specific field surveys. It is likely that these interview setups, being centred on this one disease, lent themselves to biased answers, resulting in a lower specificity. In the present study the questionnaires were self-administered and oriented towards community problems instead of being disease-specific.

For preparing such a questionnaire, a knowledge of the basic health determinants and of the pattern of disease perception in the area is essential in order to propose lists of diseases which are relevant and understandable. In the Kilombero District, this knowledge was available after a comprehensive longitudinal community health and disease perception survey in Kikwawila village. ${ }^{20,6}$ Certain conditions, such as skin and eye diseases, caries and malnutrition were shown by clinical and field investigations to be highly prevalent, but these were not recognized as health problems by the population. Disease and ill-health are not synonymous, their interrelation being influenced by cultural factors. ${ }^{30}$ The proposed list of diseases and symptoms in the questionnaires tried to integrate both elements.

A total of 77 headteachers and 44 party chairmen returned the forms, properly completed, as judged by completeness and consistency checks. For the children's questionnaire, less than $5 \%$ of the answers were 'don't know', which suggested that the children understood the questions. The evaluation of the questionnaire's efficiency was done only indirectly, by comparison with parasitological reference data. No direct cross-checking of the interviews was possible because of the study design. Also, we had no control over the distribution of the questionnaire by the District Education Officer.

Calculation of the diagnostic performance of the 


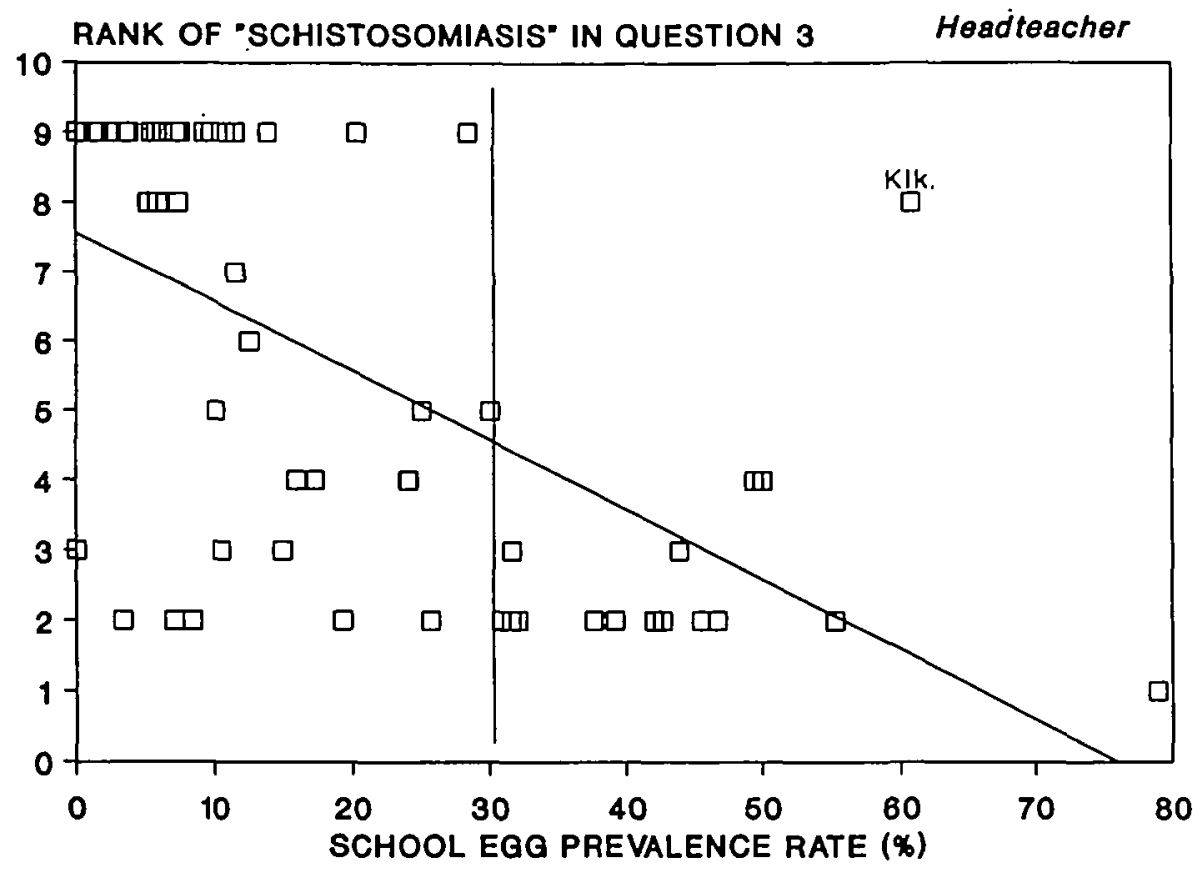

FIOURE 4 Correlation (with regression line) between the school parasitological prevalence rate and the rank given by the headteacher to schistosomiasis (question three-priority diseases for control). Fifty-six schools of the Kilombero Distriat. Note the 'high prionty limit' at $30 \%$ prevalence rate. Kik. = Kikwawila.

questionnaires (Table 3) allowed the definition of the predictive power of people's own disease perception for urinary schistosomiasis. For both the headteachers' and the party chairmen's questionnaire, the third question ('priority for control') showed the best diagnostic performance. For this question, with no proposed list to choose form, the respondents often used 'blood in urine' instead of 'schistosomiasis', suggesting that the disease and its main symptom are strongly associated in the respondents' minds. This is consistent with the observation in other surveys in the same area that microhaematuria, measured by reagent sticks, was better understood as a disease indicator than the parasite's eggs. ${ }^{24}$ For the children's questionnaire, both questions showed almost similar diagnostic performances, although the frequency of answers 'I had schistosomiasis' was statistically higher than the answer 'I had blood in urine'. The difference could be explained by the fact that other symptoms of urinary schistosomiasis (mainly dysuria and lower abdominal pain) were not included in question one. These latter symptoms are more likely than haematuria to bring a child to a health service for treatment and to make him/her consider schistosomiasis as a major personal problem.

Due to their high negative predictive values (mostly $>90.0 \%$ ), questionnaires allowed the schools that do not have a problem of urinary schistosomiasis to be excluded rapidly and with acceptable accuracy. With such an initial, rapid and inexpensive district-wide screening, scarce resources can be concentrated on high-risk schools. As the children's questionnaire relies on the answers of many individuals, rather than on a single person, it seems appropriate to recommend its use rather than the teachers' questionnaire for screening.

The results of the questionnaires are not accurate in quantifying the infection rates (Figures $3 a$ and $3 b$ ) and a second quantitative screening step is therefore necessary to obtain the prevalence rates of the positive schools as well as to identify positive children for treatment. As the use of mobile laboratories was found to be unrealistic with the resources available at district level, a two-step methodology was designed and applied in the neighbouring Kilosa District. ${ }^{31}$ For collecting the reference endemicity data it relied on teachers performing reagent stick testing. This approach was shown to be operationally feasible and very cost-efficient.

Based on the data from the different approaches, an attempt was made to calculate the total number of schistosomiasis cases in the district. The health statistics reported an average of 2392 cases per year. From the children's questionnaire, an extrapolation to the whole school population of the district $(n=22108)$ 


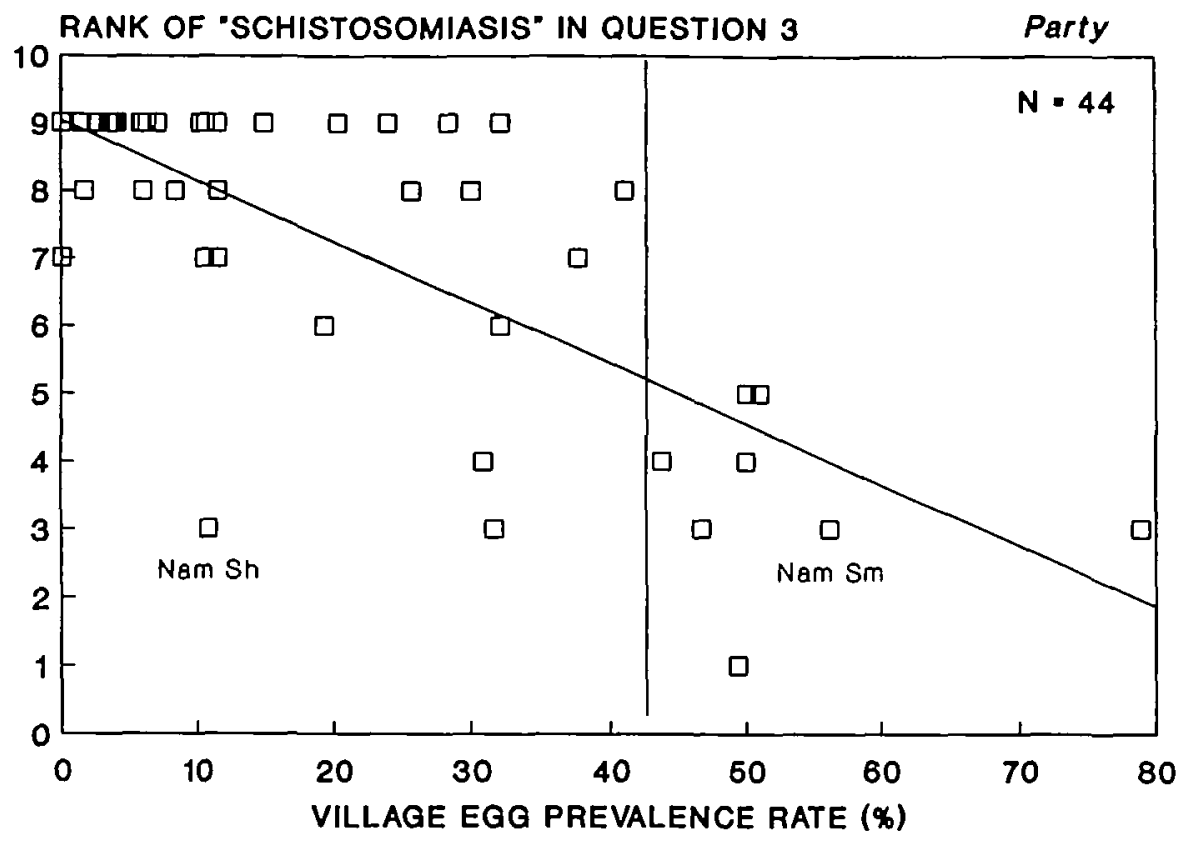

FIGURE 5 Correlation (with regression line) between the village egg prevalerce rate and the rank given by the party chairman lo schistosomiasis (question 3-priority diseases for control). Forty-four party branches of the Kllombero Distruct. Note the 'high priority limit' at $43 \%$ prevalence rate. Nam Sh a Namwawala, S. haematobium infection rate. Nam $S m=$ Namwawala, $S$. mansone infection rate.

suggested that 4616 schoolchildren would have reported infection. An extrapolation from the parasitological data, taking into account that urine filtration misses about one-third of the egg-positive people on a single testing day, ${ }^{24}$ gave a figure of 5300 infected schoolchildren. It is evident that the two approaches in the schools underestimated the total number of infected people, as younger and older people were excluded frem testing. However, these calculations showed (i) that the school questionnaires gave a good approximate figure for the number of infected school- children in the district and (ii) that the health statistics underestimated the total number of infected people in the district by at least a factor of three.

The teachers' and party chairmen's ranking of their priority diseases for control (Figures 5 and 6 ), although based on the perception of a single person per village, was found to be a useful indicator for schistosomiasis planning at district level. Clearly, the importance of schistosomiasis for the community was dependent on the prevalence rate, and the 'high priority limit', as it was defined, could be a relevant element when for-

TABLE 4 Operational features and cast-comparisons of the four approaches for district-wide screening of urinary schistosomiasis. A 'unit' is either a health service, a school, or a party branch

\begin{tabular}{|c|c|c|c|c|}
\hline Approach & $\begin{array}{c}1 \\
\text { Health } \\
\text { statistics }\end{array}$ & $\begin{array}{c}2 \\
\text { School } \\
\text { questionnaires } \\
\text { (teacher + children) }\end{array}$ & $\begin{array}{c}3 \\
\text { Party } \\
\text { questionnaire }\end{array}$ & $\begin{array}{c}4 \\
\text { Mobile } \\
\text { laboratory }\end{array}$ \\
\hline $\begin{array}{l}\text { Return rate (coverage) } \\
\text { No. of children screened }\end{array}$ & $\begin{aligned} & 22 / 22 \\
&= 100 \% \\
& n / a^{*}\end{aligned}$ & $\begin{array}{c}77 / 77 \text { and } 75 / 77 \\
100 \text { and } 97.4 \% \\
6772\end{array}$ & $\begin{aligned} & 44 / 51 \\
= & 86.3 \% \\
& n / a^{*}\end{aligned}$ & $\begin{aligned} & 5677 \\
= & 72.7 \% \\
& 469\end{aligned}$ \\
\hline $\begin{array}{l}\text { Cost of approach (USS) } \\
\text { Cost per surveyed unit } \\
\text { Cost per surveyed child }\end{array}$ & $\begin{array}{r}80 \\
3.60 \\
n / a^{*}\end{array}$ & $\begin{array}{r}270 \\
3.50 \\
0.04\end{array}$ & $\begin{array}{l}80^{\circ} \\
1.80 \\
n / a^{\circ}\end{array}$ & $\begin{array}{r}5200 \\
92.90 \\
1.16\end{array}$ \\
\hline Screening time & 1 week & 6 weeks & 12 weeks & 15 weeks \\
\hline
\end{tabular}

* $\mathrm{N} / \mathrm{a}=$ not applicable 
mulating a control strategy. One should however be aware that the choice of the respondents influences the results, as the comparison of the headteacher and the party questionnaires clearly showed.

The efficiency of the questionnaire approach relied heavily on a well-structured and efficient administrative system. The Tanzanian primary education system was found to meet these criteria, because of the high schooling rate in the country and its good organization at district level. The village chairmen approach showed a lower coverage (only 38 out of 45 villages) and a longer return time.

Financial cost calculations showed clearly that questionnaires are very cost efficient and that they lower the screening costs to a level which is affordable by district or regional authorities ( $3.5 \mathrm{US} \$ /$ school). Once the forms are printed, the necessary staff to execute the survey are already available at district level. This is not the case for the parasitological screening approach, which requires not only high financial and material input, but also requires specialized teams.

The diagnostic efficiency of the questionnaire approach for $S$. mansoni infections is as yet unknown. In Tanzania, as in most endemic settings, areas of intestinal schistosomiasis transmission are also endemic for malaria, intestinal parasites, and bacterial and viral gastro-enteritis, and these diseases are associated with signs and symptoms similar to intestinal schistosomiasis. A study in the Lake Victoria area ${ }^{32}$ showed that diarrhoea and hepatomegaly were significantly associated with $S$. mansoni infections, but that these symptoms were not specific enough as diagnostic criteria. Other authors found a significant association between heavy infections ( $>1000 \mathrm{eggs} / \mathrm{g}$ ) and abdominal pain, diarrhoea and/or hepatomegaly ${ }^{33.34}$ but they did not investigate the diagnostic power of these signs.

The repeated use of questionnaires for monitoring control programmes must be carefully considered. It is likely that disease perception and the setting of priorities will be affected by any type of control activity. In this respect it was interesting to note that the village of Kikwawila (Figure 4), where schistosomiasis control activities had already been taking place, ${ }^{15}$ gave a low priority to the control of schistosomiasis, although the prevalence rate was still found to be high.

The use of questionnaires offers a simple tool not only for the identification of areas of high risk for schistosomiasis, but also for other communicable diseases with well perceived signs and symptoms. Questionnaires can also produce information for the prioritization of different health problems, and of health among other community issues. This is a necessary basis on which to build community participation for an inter- vention programme. ${ }^{14}$ A similar approach will be tested with bancroftian filariasis, onchocerciasis and trypanosomiasis, and might show the value of this approach.

It is likely that the questionnaire approach would not be so easy to use in countries with a less highly-organized educational and political system and a lower rate of school attendance and literacy than Tanzania. However, modifications of the procedure using other groups, e.g. women's organizations, might well be possible.

A multi-country study is now being implemented with the support of WHO/Tropical Diseases Research to validate the questionnaire approach in eight different endemic settings in Africa.

\section{ACKNOWLEDGEMENTS}

Our sincere thanks go to the health staff, party chairmen, teachers and schoolchildren of the Kilombero District, for their friendly and efficient collaboration. Our special thanks go to Mr E. Ngonyani, District Education Officer, for his excellent support. Thanks also to Dr G. Lwihula for his help in designing the questionnaires and to $J$. Jenkins for reviewing the manuscript. Research clearance was granted by the Tanzanian Commission for Science and Technology (UTAFITI) as per Ref. NSR/RA47 of 18 June 1984. We would also like to thank the National Institute of Medical Research (NIMR), Tanzania (Director General Prof. W. L. Kilama) for permission for publication. This work was partly supported by the Swiss Directorate for Technical Cooperation and Humanitarian Aid (SDC). One of us (CL) was supported by the 'Rudolf Geigy Stiftung zu Gunsten des Schweizerischen Tropeninstituts.'

\footnotetext{
REFERENCES

'Jordan P, Webbe G. Schistosomiasis. Epidemiology, treatment and control. London, Heinemann Medical Books, 1982.

${ }^{2}$ Vaughan P, Mills A, Smith D. District healih planning and management. EPC Publication 2. London, Evaluation and Planning Centre, London School of Tropical Medicine and Hygiene. 1984.

'Feachem R G, Wendy J G, Timaeus J. Identifying health problems and health research prorities in developing countries. Paper for the Independent International Commission on Health Research for Developing Countries. London, 1987.

- Tanner M. District-level data collection and use. Paper prepared for the Independent International Commission on Health Research for Development. Boston, Harvard School of Public Health, 1988.

SNichter M. Project community diagnosis: participatory research as a first step towards community involvement in primary health care. Soc Sci Med 1984; 19: 237-52.
} 
- Degrtmont A, Lwihula G K, Mayombana C, Burnier E, de Savigny D H, Tanner $M$. Longitudinal study on the health status of children in a rural Tanzanan community: comparison of community-based clinical examinations, the diseases seen at village health posts and the perception of health problems by the population. Acta Trop (Basel) 1987; 44: 175-91.

' Jackson L C. Malaria in Liberian children and mothers: biocultural perceptions of illness versus clinical evidence of disease. Soc Sci Med 1985; 20: 1281-87.

'Greenwood B M, Bradley A K, Greenwood A M, et al. Mortality and morbidity from malaria among children in a rural area of the Gambia, West Africa. Trans R Soc Trop Med Hyg 1987; 81: 478-86.

${ }^{9}$ Zumstein A. A study of some factors influencing the epidemiology of urinary sctistosomiasis at Ifakara (Kılombero District, Morogoro Region, Tanzania). Acta Trop (Basel) 1983; 40: 187-204.

${ }^{10}$ Lwihula G K. Human behaviour factors associated with transmission and control of Schistosome haematobium in Ifakara area, Morogoro, Tanzana. Ph.D. thesis, University of London, 1985.

"Kloos H, Sidrak W, Michael A M, Mohareb E W, Higashi G I. Disease concepts and medical practices relating to schistosomiasis heamatobium in Upper Egypt. J Trop Med Hyg 1982; 85: 99-107.

${ }^{12}$ Tanner M, de Savigny D. Monitoring of communtiy health status: experience from a case study in Tanzania Acta Trop (Basel) 1987; 44: 261-70.

${ }^{13}$ Haerd, F. Afrikanische Heilpflanzen. Die Eingeborenen-Heilpflanzen des Ulanga Distriktes Tanganyikas (Ost-Afrika). Acta Trop (Basel) 1964; Suppl 8: 334.

${ }^{14}$ Tanner $M$. From the bench to the field: control of parasitic infections within primary health care. Parasitology 1989; 99: S81-S92.

${ }^{15}$ Suter R. The plant molluscicide Swarzia madagascanensis and its application in transmisston control measures against Schisto. soma haematobium, experience from Kikwawila (Kilombero Disfrict, Tanzanta). Ph.D. thesis, University of Basle, 1986.

${ }^{16}$ Ministry of Health Proposed policy for the control of schistosomiasis in Mainland Tanzania. Dar es Salaam, 1985.

${ }^{17} \mathrm{~J}$ atzold R, Baum E. The Kilombero Valley, characieristic features of the economic geography of a semi-humid East Afrcan flood plain and its margins. München, Weltforum Verlag, 1968.

${ }^{13}$ Tanner M, Degrémont A, de Savigny D, Freyvogel T A, Mayombana C, Tayari S. Longitudinal study on the health status of children in Kıkwawila village, Tanzania: study area and design. Acta Trop (Basel) 1987; 44: 119-37.

- Clyde D F. Malaria in Tanzania. London, Oxford University Press, 1967.

${ }^{20}$ Tanner M, Burnier E, Mayombana C, et al. Longitudinal study on the health status of children in a rural Tanzanian community: parasitoses and nutrition followng control measures against intestinal parasites. Acta Trop (Basel) 1987; 44: 137-75.

"Sturrock R F. The development of irrigation and its influence on the transmission of bilharziasis in Tanganyika. Bull WHO 1965; 32: 225-36.

${ }^{2}$ Marti H P, Tanner M, Degremont A A, Freyvogel T A. Studies on the ecology of Bulinus globosus, the intermediate host of Schistosoma haematobium in the Ifakara area, Tanzania. Acta Trop (Basel) 1985; 42: 171-87.

${ }^{2}$ deSavigny D, Burnier E, Mayombana C, Tanner M, Degrémont A, Mgeni A F. Schistosomiasis morbidity at one year following selective chemotherapy with Praziquantel. Proceedings of the annual NIMR conference. Dar es Salaam, 1986.

${ }^{24}$ Lengeler C. Individual and community diagnosis of urinary schistosomiasis and their relevance for disease control: a study in an endemic area of south-eastern Tanzania. Ph.D. thesis, University of Basel, 1989.

${ }^{2}$ WHO. The control of schistasomiasis. Report of a WHO Expert Committee. Technical reports series 728. Geneva, 1985.

${ }^{26}$ Galen R S, Gambino S R. Beyond nomality: the predictive value and efficiency of medical diagnoses. New York, John Wiley and Sons, 1975.

${ }^{27}$ Tanner M. Evaluation and monitoring of schistosomiasis control. Trop Med Parasit 1989; 40: 207-13

${ }^{23}$ Mott K E, Dixon H, Osei-Tutu E, England E C, Ekue K, Tekle A. Indirect screening for Schistosoma haematobium infection: a comparative study in Ghana and Zambia. Bull WHO 1985; 63: $135-42$.

${ }^{\infty}$ Saviolı L, Mott K E Urinary schustosomiasis on Pemba Island: lowcost diagnosis for control in a primary health care setting. Parasitol Today 1989; 5: 333-7.

${ }^{30}$ Heggenhougen H K, Shore L. Cultural components of behavioural epidemiology: implications for primary health care. Soc $S c i$ Med 1986; 22: 1235-45.

${ }^{31}$ Lengeler $C$, Kilima P, Mshinda H, Morona D, Hatz C, Tanner $M$. Rapid low-cost, two-step me thod to screen for urinary schistosomiasis at district level: the Kilosa experience. Bull WHO 1991, 69: 179-89.

${ }^{3}$ Gabone R M, Rugemalıla J B. The morbidity effects of schistosomia. sis mansoni in an endemic community on Kome Island of Lake Victoria, Tanzania. Proceedings of the annual NIMR conference. Dar es Salaam, 1987.

${ }^{3}$ Arap Siongok T K, Mahmoud A A F, Ouma J H, et al. Morbidity in schistosomiasis mansoni: study of a community in Machakos, Kenya. Am J Trop Med Hyg 1976; 25: 273-83.

${ }^{4}$ Gryseels B. The relevance of schistosomiasis for public health. Trop Med Parasit 1989; 40: 134-42.

(Revised version received November 1990) 